\section{The X-ray Structure of $\mathbf{N}_{4} \mathbf{P}_{4} \mathbf{C l}_{7}\left(\mathbf{N P P h}_{3}\right)$ - a Novel Conformation of the $\mathbf{N P P h}_{\mathbf{3}}$ Group}

\author{
Y. Sudhakara Babu and H. Manohar \\ Department of Inorganic and Physical \\ Chemistry, Indian Institute of Science, \\ Bangalore 560012, India
}

\section{T. Stanley Cameron}

Department of Chemistry, Dalhousie University, Halifax, Nova Scotia, Canada B3H 4J 3

and

Robert A. Shaw

Department of Chemistry, Birkbeck College, Malet Street, London, WClE 7 HX, UK

Z. Naturforsch. 33 b, 682-683 (1978); received March I3, 1978

Heptachloro(triphenylphosphazenyl) cyclotetraphosphazatetraene, X-ray, Crystal Structure, Triphenylphosphazenyl Group Conformation

The X-ray crystal structure of heptachloro(triphenylphosphazenyl)cyclotetraphosphaza. tetraene $\mathrm{N}_{4} \mathrm{P}_{4} \mathrm{Cl}_{7}\left(\mathrm{NPPh}_{3}\right)$ reveals a novel conformation (tending to Type III) of the triphenylphosphazenyl group with respect to the adjacent ring segment. This observation is contrasted with the structure of $\mathrm{N}_{3} \mathrm{P}_{3} \mathrm{Cl}_{5}\left(\mathrm{NPPh}_{3}\right)$ where a Type I conformation is observed.

Phosphazenylcyclophosphazenes have aroused a good deal of attention lately. Basicity studies [1] revealed two types of behaviour, which were suggested to relate to endocyclic and exocyclic protonation. It was deduced that these were functions of the relative conformation of the triphenylphosphazenyl substituent with respect to the local ring NPN segment, to which they were attached. These were called Type I and Type II conformations and have been discussed in detail elsewhere $[2,3]$. Briefly, Type I would be associated with the $\mathrm{N}-\mathrm{P}$ bond of the substituent being approximately perpendicular to the axis of the adjacent $P-X$ bond (where $X$ is the first atom of the other substituent on the same phosphorus atom), whilst in Type II it is coplanar with this. The former has been recently reported for $\mathrm{N}_{3} \mathrm{P}_{3} \mathrm{Cl}_{5}\left(\mathrm{NPPh}_{3}\right)$ [4] and the latter for $\mathrm{N}_{3} \mathrm{P}_{3} \mathrm{Cl}_{4} \mathrm{Ph}\left(\mathrm{NPPh}_{3}\right)$ [5]. Type III conformations (intermediate between Types I and II) were recently described for geminal bisdimethylamino and diphenyl groupings [3]. We now report the X-ray structure of $\mathrm{N}_{4} \mathrm{P}_{4} \mathrm{Cl}_{7}\left(\mathrm{NPPh}_{3}\right)$ which exhibits a conformation tending to Type III.

The compound, $\mathrm{N}_{4} \mathrm{P}_{4} \mathrm{Cl}_{7}\left(\mathrm{NPPh}_{3}\right)$, crystallises in the triclinic space group $\mathrm{P} \overline{\mathbf{l}}$ with $a=8.996$,

Requests for reprints to Dr. H. Manohar, Department of Inorganic and Physical Chemistry, Indian Institute of Science, Bangalore 560012, India. $b=9.804, c=16.477 \AA, a=100.72, \beta=91.22$, $\gamma=100.06^{\circ}$ and $Z=2$. Intensity data were collected on a CAD-4 diffractometer by the $\omega-2 \theta$ scan technique using monochromated MoKa radiation. Of the 4199 independent reflections measured, 3301 reflections were considered to be above the threshold $[\mathrm{I} \geqslant 3 \sigma(\mathrm{I})]$. The structure has been solved by direct methods using Multan [6] and refined by least squares to an R-index of 0.043 using anisotropic temperature factors for all atoms except hydrogens. Hydrogens have been included in the calculations by placing them at the positions deduced from molecular geometry.

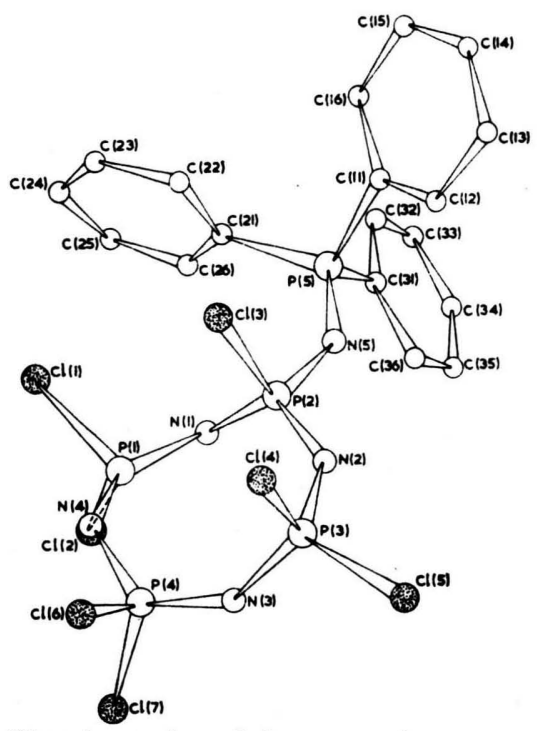

Structure viewed down $a$-axis.

A view of the molecule down the $a$-axis and the bond lengths are shown in the Figures. The phosphazene ring exhibits a conformation intermediate between crown and saddle or crown and chair. All the four phosphorus atoms lie in a plane, the maximum deviation from planarity being $0.03 \AA$. N(1), $\mathrm{N}(2)$ and $\mathrm{N}(3)$ lie on one side of this plane at distances $0.48,0.28$ and $0.49 \AA$ respectively and $\mathrm{N}(4)$ lies on the other side at a distance of $0.50 \AA$. This conformation is similar to that of a nongeminally substituted dimethylamino derivative, $\mathrm{N}_{4} \mathrm{P}_{4} \mathrm{Cl}_{4}\left(\mathrm{NMe}_{2}\right)_{4}$ [7]. The non-geminal $\mathrm{P}-\mathrm{Cl}$ bond and the two endocyclic $\mathrm{P}-\mathrm{N}$ bonds adjacent to the $\mathrm{NPPh}_{3}$ substituted phosphorus atom are the longest bonds of their kind in this molecule. The exocyclic $\mathbf{P}-\mathrm{N}$ bond lengths are not equal, but the difference ( $<3$ e.s.d.'s) may not be significant. The geminal bond lengths $\mathrm{P}(3)-\mathrm{Cl}(5)$ and $\mathrm{P}(3)-\mathrm{Cl}(4)$, however, are significantly different. Similar differences in geminal $\mathrm{P}-\mathrm{Cl}$ bond lengths have been observed in gem- $\mathrm{N}_{3} \mathrm{P}_{3} \mathrm{Ph}_{2} \mathrm{Cl}_{4}$ [8] and $\mathrm{N}_{3} \mathrm{P}_{3} \mathrm{Cl} 4 \mathrm{Ph}\left(\mathrm{NPPh}_{3}\right)$ [5].

The most interesting feature in this structure is the conformation of the $\mathrm{NPPh}_{3}$ group. In the corresponding trimer, $\mathrm{N}_{3} \mathrm{P}_{3} \mathrm{Cl}_{5}\left(\mathrm{NPPh}_{3}\right)$, the $\mathrm{N}-\mathrm{P}$ 
bond of the substituent is nearly perpendicular (Type I conformation) to the adjacent $\mathrm{P}-\mathrm{Cl}$ bond, the torsion angle $\mathrm{Cl}(1)-\mathrm{P}(2)-\mathrm{N}(4)-\mathrm{P}(4)$ being $\mathbf{8 3}^{\circ}$.

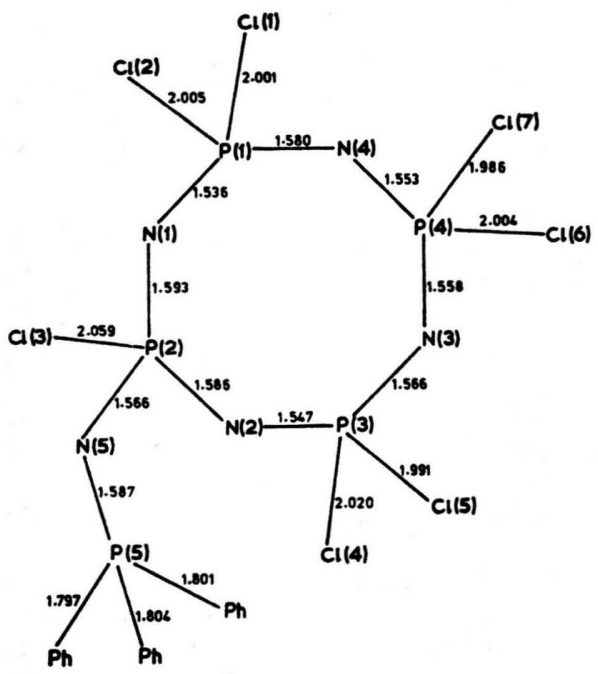

Bond lengths ( $\AA$ ).E. s. d.'s for the bond lengths $\mathrm{P}-\mathrm{Cl}$ $0.004, \mathrm{P}-\mathrm{N} 0.009, \mathrm{P}-\mathrm{C} 0.01 \AA$.
(Numbering of atoms is as given in Figure of Reference [4].) On considerations discussed previously [3] one would have expected a similar Type I conformation for the $\mathrm{NPPh}_{3}$ group in the present compound as well. This is, however, not found to be the case, the values for the torsion angles $\mathrm{N}(1)-\mathrm{P}(2)-\mathrm{N}(5)-\mathrm{P}(5), \quad \mathrm{N}(2)-\mathrm{P}(2)-\mathrm{N}(5)-\mathrm{P}(5) \quad$ and $\mathrm{Cl}(3)-\mathrm{P}(2)-\mathrm{N}(5)-\mathrm{P}(5)$ being $59^{\circ},-172^{\circ},-58^{\circ}$ respectively. The deviation from Type I towards Type III conformation appears to be due to steric factors. The contact distances $\mathrm{P}(5)-\mathrm{N}(1)$ and $\mathrm{P}(5)-\mathrm{Cl}(3)$ are 3.52 and $3.71 \AA$ respectively, the corresponding distances in $\mathrm{N}_{3} \mathrm{P}_{3} \mathrm{Cl}_{5}\left(\mathrm{NPPh}_{3}\right)$ being 3.49 and $3.97 \AA$ respectively. If the $\mathrm{NPPh}_{3}$ group in the present structure were to assume an exact Type I conformation [i.e. $\mathrm{Cl}(3)-\mathrm{P}(2)-\mathrm{N}(5)-\mathrm{P}(5)$ $\approx 90^{\circ}$, the contact distance $\mathrm{P}(5)-\mathrm{N}(1)$ would have been too short. Therefore in order to avoid this unfavourable situation, the $\mathrm{NPPh}_{3}$ group has taken up a conformation which is sterically more favourable.

The authors wish to thank Dr. S. S. Krishnamurthy, Indian Institute of Science, Bangalore for a gift of $\mathrm{N}_{4} \mathrm{P}_{4} \mathrm{Cl}_{7}\left(\mathrm{NPPh}_{3}\right)$ which was prepared as described earlier [9]. One of us (T.S.C.) wishes to thank the National Research Council of Canada for financial support.
[1] M. Biddlestone, S. N. Nabi, and R. A. Shaw, J. C. S. Dalton 2634 (1975).

[2] R. A. Shaw, Pure and Appl. Chem. 44, 317 (1975).

[3] R. A. Shaw, Z. Naturforsch. 31 b, 641 (1976).

[4] Y. S. Babu, T. S. Cameron, S. S. Krishnamurthy, H. Manohar, and R. A. Shaw, Z. Naturforsch. 31 b, 999 (1976).

[5] M. Biddlestone, R. A. Shaw, G. J. Bullen, and P. E. Dann, Chem. Commun. 56 (1974).
[6] G. Germain, P. Main, and M. M. Woolfson, Acta Cryst. A 27, 368 (1971).

[7] G. J. Bullen and P. A. Tucker, J. C. S. Dalton, 2437 (1972).

[8] N. V. Mani, F. R. Ahmed, and W. H. Barnes, Acta Cryst. 19, 693 (1965).

[9] M. Biddlestone and R. A. Shaw, J. C. S. Dalton, 2740 (1973). 